Article

\title{
Comparing Social Media Observations of Animals During a Solar Eclipse to Published Research
}

\author{
Robert Ritson, Dustin H. Ranglack $(1)$ and Nate Bickford * \\ Department of Biology, University of Nebraska at Kearney, Kearney, NE 68849, USA; \\ ritsonrj@lopers.unk.edu (R.R.); ranglackdh@unk.edu (D.H.R.) \\ * Correspondence: bickfordna@UNK.edu
}

Received: 25 November 2018; Accepted: 3 February 2019; Published: 14 February 2019

check for updates

Simple Summary: Solar eclipses offer a unique opportunity to evaluate the relative influence of unexpected darkness on behavior of some species of animals due to their sudden interference with local light levels and meteorology. The Great American Solar Eclipse of 21 August 2017 rekindled curiosity in animal behavior during an eclipse. What made this most recent eclipse especially unique was the fact that it occurred over a relatively populous region of the globe, with approximately 12 million people living in the path of totality, garnering a lot of publicity. This immense viewership created a unique opportunity to gather a large amount of observations simultaneously across the eclipse. A comparison of informal observations of animal behavior during solar eclipse from social media (i.e., March for Science Facebook discussion) to those conducted scientifically (published literature) can elucidate how well this topic is being covered. Describing which species and behaviors are covered in each source can reveal gaps in the literature which can emphasize areas for future research. Our understanding of animal behavior can benefit beyond the narrow scope of such studies by characterizing the complex variations in behavioral response which result from a solar eclipse.

Abstract: A wide variety of environmental stimuli can influence the behavior of animals including temperature, weather, light, lunar and seasonal cycles, seismic activity, as well as other perturbations to their circadian rhythm. Solar eclipses offer a unique opportunity to evaluate the relative influence of unexpected darkness on behavior of animals due to their sudden interference with local light levels and meteorology. Though occasionally bizarre, modern studies have lent support to the idea that at least some individuals of certain species display altered behavior during these events. A comparison of informal observations of animal behavior during solar eclipse from social media (i.e., March for Science Facebook discussion) to those conducted scientifically (published literature) can elucidate how well this topic is being covered. Describing which species and behaviors are covered in each source can reveal gaps in the literature which can emphasize areas for future research. We enumerated a total of 685 observations of approximately 48 different types of animals reacting to the 2017 Great American Solar Eclipse from over 800 posts on the discussion. The animals most frequently reported on social media as reacting to the eclipse were invertebrates (40\% of social media observations) and birds ( $35 \%$ of social media observations). A total of 26 published studies recorded 169 behavior observations of approximately 131 different animal species. The group with the highest number of observations in the literature were birds with 62 records ( $37 \%$ of literature observations). Most observations reported decreases in activity (38.7\% of bird observations) followed by increases in vocalization ( $24.2 \%$ of bird observations). There were approximately 30 different species of invertebrate observed ( $24 \%$ of literature observations), most frequently reported of which were zooplankton ( $14.6 \%$ of invertebrate observations).

Keywords: eclipse; solar; animals; behavior 


\section{Introduction}

A wide variety of environmental stimuli can influence the behavior of animals including temperature, weather, light, lunar and seasonal cycles, seismic activity, as well as other perturbations to their circadian rhythm [1]. The manner in which animals respond to these varying conditions is often related to their specific life history [2], including physiology and orientation-navigational behaviors [3]. Solar eclipses offer a unique opportunity to evaluate the relative influence of unexpected darkness on relatively prolonged behavior due to their sudden interference with local light levels and meteorology [4]. However, planning experimental research studies around these novel events is often difficult. Although they occur somewhere on Earth two to five times in a given calendar year, a given location will experience total darkness only once every 350 years for a maximum totality duration of seven minutes although typically around three minutes [5]. The mechanics responsible for these phenomena are well understood [6], but our comprehension of how or why animals react to such events is surprisingly limited. Despite the meager attention, studies of animal behavior during solar eclipses have been published for a variety species.

The first recorded observation of an animal responding to a solar eclipse, to our knowledge, was made in mid-1500 noting "birds falling out of the sky and ceasing to sing" [7]. Though occasionally bizarre, modern studies have lent support to the idea that at least some individuals of certain species display altered behavior during these events. In addition to further observations on birds $[8,9]$, the list of investigated species includes insects [10-14], aquatic invertebrates [15-19], primates [20-23], fish [24,25], rodents [26,27], bats [28,29], and lizards [30,31], as well as larger mammals like blue bull antelope [32] and dairy cattle [33]. However, conclusions vary by study and species. For example, the studies on bats reach similar conclusions which suggest no change in behavior [28,29] but observations of chimpanzees differ [20,22]. Studies of animal behavior during solar eclipses tend to be brief in length compared to typical studies in this field and usually rely on relatively simple observational protocols to document activity. However, recent studies have incorporated more sophisticated methods to explore this topic including radar documenting the activity of flying animals [34] and acoustic monitoring of calling activities [35].

The Great American Solar Eclipse of August 21, 2017 rekindled curiosity in animal behavior during an eclipse [34,35]. What made this most recent eclipse especially unique was the fact that it occurred over a relatively populous region of the globe, with approximately 12 million people living in the path of totality—garnering a lot of publicity [36] — many of whom own domestic animals. This immense viewership created a unique opportunity to gather a large amount of animal observations simultaneously across the eclipse. Although more efficient and scientifically robust methods exist for formally procuring observations (i.e., surveys, mobile applications, etc.), informal notes are often overlooked. Since this topic has received little formal attention, informal accounts can offer useful insight for what future work should address. By reviewing social media posts concerning animal behavior during the 2017 solar eclipse, species or behaviors not otherwise considered by scientists may be procured. We chose to explore a Facebook discussion post on the March for Science page which solicited observations of animal behaviors during the eclipse [37]. This social media platform also lends itself to detailed statements than others which have fixed character limits (i.e., Twitter). It was inferred that members of this group would not be restricted to a single geographic area, thus increasing the region observed. Although contributed posts were usually nonspecific, these anecdotal observations have the potential to expose behaviors or species not currently addressed in the literature. These may indicate which species should be focused on for future studies of animal behavior during solar eclipses and how such investigations may be improved.

The objective of this investigation was to compare informal observations of animal behavior during solar eclipse from social media (i.e., March for Science Facebook discussion) [37] to those conducted scientifically (published literature) in order to elucidate how well this topic is being covered. We describe which species and behaviors the literature and social network inputs identify and emphasize areas for future research. 


\section{Methods}

Social media observations were enumerated from 800 posts on the March for Science Facebook discussion and those from scientific literature came from 26 published studies which utilized observational protocols [37]. The published research was procured using the search terms "animal behavior during a solar eclipse" in Google Scholar, and by examining the literature cited in the studies identified by the Google Scholar search. The search results were screened to ensure a response was identified. Studies which concluded no behavioral response to the solar eclipse were omitted because it was presumed that the general public was less likely to report responses when none could be identified. Published studies of this type tended to be relatively brief and sample size was limited to those accessible through our university server and published in English.

In order to compare animal behavior observations obtained through diverse methods and a variety of sources, including social media [37] and published research, we independently classified responses into broader categories to facilitate comparison. We labeled a vocalization as any behavior associated with sound or an activity if it referred to movement. If behavior was described as commencing with the onset of an eclipse it was categorized as an increase and those associated with ceasing an activity during the eclipse were called decreases. This resulted in a total of four behavior classifications: vocalization increase, vocalization decrease, activity increase, and activity decrease. Animals noted in observations as "heading to the roost" or similar remarks were classified as decreases in activity since the overall reaction was to lessen their movement. We used these simplistic characterizations to create a common means of comparison across multiple diverse species. All characterizations were coded by two individuals—one coding the social media observations and the other the published literature-to maintain independence between the data sets. To reduce the potential for errors and coder bias, the two consulted with each other frequently to ensure they were consistent in how they coded different observations. While more sophisticated behavioral classifications would be advantageous in future investigations, we believed general characterizations were more appropriate given the diversity of species included in these observations and the potential unreliability of social media data.

Instances of a behavioral occurrence were enumerated by species and behavior classification with no regard for the number of individuals, as each report was counted as a single observation. However, if individuals in a group displayed different or multiple behaviors, each behavior was counted as a separate record. For example, if frogs were reported to both increase vocalization and activity, the record was counted twice: once for the increase in vocalization and once for the increase in activity. The finest taxonomic classification reported for an animal exhibiting a behavior was used as the animal name, but many online observations simplistically reported broader names such as "birds" or "frogs." The differing scales of species classification alter the overall count of species behaviors, however assessing observations by animal group alleviates this issue. Additionally, given that we have no knowledge of the scientific knowledge of the social media participants, we did not feel we could fully trust their species-level identification. We classified animals in each observation as amphibian, bird, fish, invertebrate, mammal, or reptile. This eliminates inconsistency in naming, accounts for the potential unreliability of social media data, and allows for broad comparisons of observations between sources in addition to maintaining taxonomic consistency with broader analyses of animal behavior [1].

\section{Results}

\subsection{Social Media: Anecdotal Observations of Behavior during the 2017 Eclipse}

A total of 685 observations of approximately 48 different types of animals reacting to the 2017 Great American Solar Eclipse were enumerated the March for Science Facebook discussion (Table 1) [37]. The animals most frequently reported on social media reacting to the eclipse were invertebrates $(40 \%$ of social media observations) and birds ( $35 \%$ of social media observations; Figure 1A). The invertebrates included 11 types of insect as well as the broader category of 'nocturnal 
insects', spiders, and slugs. Crickets and cicadas received the highest proportion of reported observations at $33.8 \%$ and $31.6 \%$ of invertebrate observations, respectively. The most frequently reported behavior for invertebrates was vocalization increasing ( $64 \%$ of invertebrate observations) followed by decreases in activity ( $24.7 \%$ of invertebrate observations; Figure 2A). Observations of birds included 15 types in addition to the broader categories of "birds" and "seabirds". The most commonly mentioned bird was chickens (15.6\% of bird observations). The behavior most frequently reported was activity increasing (31.7\% of bird observations) followed by decrease in vocalization $(25.9 \%$ of bird observations; Figure 2A). Observations of mammals comprised $20 \%$ of the social media posts (Figure 1A), with the most commonly mentioned of the 15 types of mammals observed being dogs ( $24.3 \%$ of mammal observations) and bats (16.9\% of mammal observations). An increase in activity was most frequently reported for mammals (64\% of mammal observations) followed by increases in vocalization (27.2\% of mammal observations; Figure $2 \mathrm{~A})$. Social media posts related to amphibians ( $2 \%$ of social media observations; Figure $1 \mathrm{~A}$ ) were comprised completely of reports of "frogs" which increased vocalization (Figure $2 \mathrm{~A}$ ) while observations of fish and reptiles ( $2 \%$ and $1 \%$ of social media observations, respectively; Figure 1A) only reported "fish" and "snakes" which increased activity (Figure 2A).

A

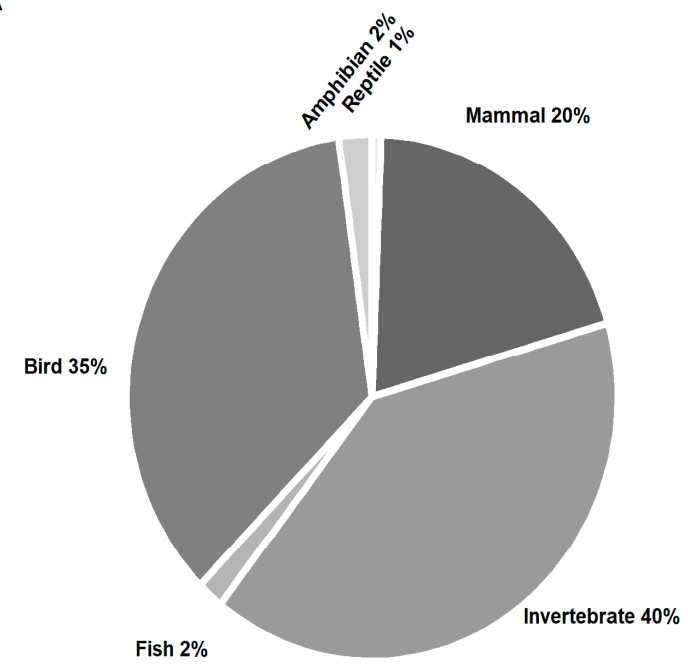

B

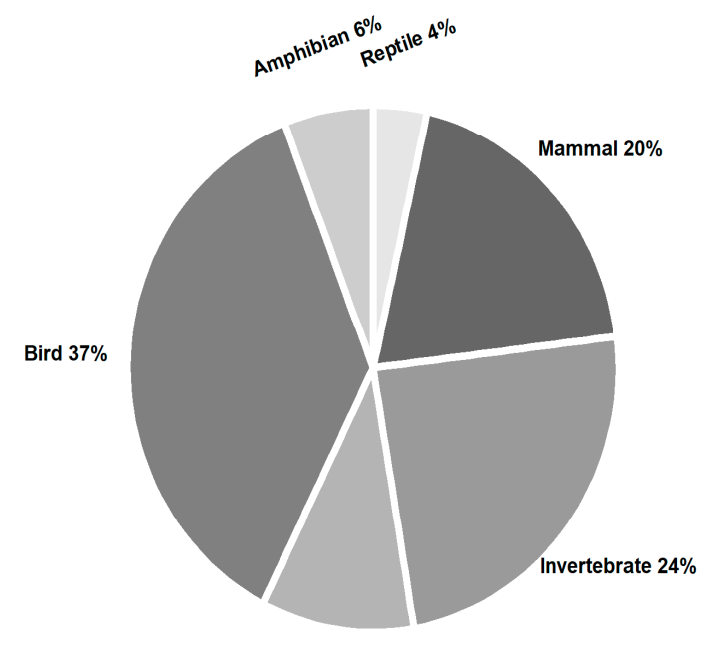

Fish $10 \%$

Figure 1. Proportions of observations made for different types of animals and behaviors recorded by social media and scientific literature. The proportion of animal groups observed recorded by social media during the 2017 Great American solar eclipse (A) and the scientific literature during multiple previous eclipses $(\mathbf{B})$ is reported as a percent of the total number of observations made for each source (social media and scientific literature each total 100\%). All observations were classified into one of six types of animals (amphibian, bird, fish, invertebrate, mammal, or reptile). 
Table 1. Total number of animal behavior observations enumerated from March for Science Facebook discussion during 2017 Great American Solar Eclipse.

\begin{tabular}{|c|c|c|c|c|c|}
\hline Animal & Group & $\begin{array}{l}\text { Vocalization } \\
\text { Increase }\end{array}$ & $\begin{array}{c}\text { Vocalization } \\
\text { Decrease }\end{array}$ & $\begin{array}{l}\text { Activity } \\
\text { Increase }\end{array}$ & $\begin{array}{c}\text { Activity } \\
\text { Decrease }\end{array}$ \\
\hline Frogs & Amphibian & 15 & 0 & 0 & 0 \\
\hline Birds & Bird & 27 & 53 & 14 & 26 \\
\hline Chicken & Bird & 13 & 9 & 7 & 9 \\
\hline Cranes & Bird & 1 & 0 & 1 & 0 \\
\hline Crows & Bird & 7 & 0 & 7 & 0 \\
\hline Geese & Bird & 2 & 0 & 3 & 3 \\
\hline Hawk & Bird & 2 & 0 & 5 & 1 \\
\hline Humming birds & Bird & 0 & 0 & 9 & 0 \\
\hline Martin & Bird & 0 & 0 & 2 & 0 \\
\hline Nighthawk & Bird & 0 & 0 & 6 & 0 \\
\hline Owl & Bird & 8 & 0 & 0 & 0 \\
\hline Pelicans & Bird & 0 & 0 & 2 & 0 \\
\hline Seabirds & Bird & 0 & 0 & 4 & 1 \\
\hline Seagulls & Bird & 1 & 1 & 3 & 0 \\
\hline Starling & Bird & 0 & 0 & 4 & 0 \\
\hline Swallow & Bird & 0 & 0 & 6 & 1 \\
\hline Turkey & Bird & 0 & 0 & 3 & 0 \\
\hline Vultures & Bird & 0 & 0 & 1 & 1 \\
\hline Fish & Fish & 0 & 0 & 12 & 0 \\
\hline Ants & Invertebrate & 0 & 0 & 3 & 0 \\
\hline Bees & Invertebrate & 0 & 2 & 18 & 5 \\
\hline Cicadas & Invertebrate & 73 & 14 & 0 & 0 \\
\hline Crickets & Invertebrate & 86 & 7 & 0 & 0 \\
\hline Dragon flies & Invertebrate & 0 & 0 & 7 & 0 \\
\hline Fireflies & Invertebrate & 0 & 0 & 10 & 0 \\
\hline Gnats & Invertebrate & 0 & 0 & 8 & 1 \\
\hline Grasshopper & Invertebrate & 0 & 0 & 0 & 1 \\
\hline Locust & Invertebrate & 2 & 0 & 0 & 0 \\
\hline Mosquitos & Invertebrate & 0 & 0 & 16 & 0 \\
\hline Nocturnal insects & Invertebrate & 15 & 0 & 2 & 0 \\
\hline Slug & Invertebrate & 0 & 0 & 1 & 0 \\
\hline Spiders & Invertebrate & 0 & 0 & 3 & 1 \\
\hline Bat & Mammal & 0 & 0 & 23 & 0 \\
\hline Cat & Mammal & 0 & 0 & 8 & 0 \\
\hline Cows & Mammal & 5 & 0 & 3 & 2 \\
\hline Coyote & Mammal & 14 & 0 & 0 & 0 \\
\hline Deer & Mammal & 0 & 0 & 7 & 1 \\
\hline Dogs & Mammal & 11 & 0 & 22 & 0 \\
\hline Dolphins & Mammal & 0 & 0 & 2 & 0 \\
\hline Elk & Mammal & 0 & 0 & 1 & 0 \\
\hline Giraffes & Mammal & 0 & 0 & 2 & 0 \\
\hline Horses & Mammal & 2 & 0 & 10 & 2 \\
\hline Prairie Dog & Mammal & 1 & 0 & 1 & 0 \\
\hline Rabbits & Mammal & 0 & 0 & 5 & 0 \\
\hline Sheep & Mammal & 0 & 1 & 1 & 0 \\
\hline Squirrels & Mammal & 0 & 1 & 2 & 5 \\
\hline Wolves & Mammal & 4 & 0 & 0 & 0 \\
\hline Snakes & Reptile & 0 & 0 & 4 & 0 \\
\hline
\end{tabular}



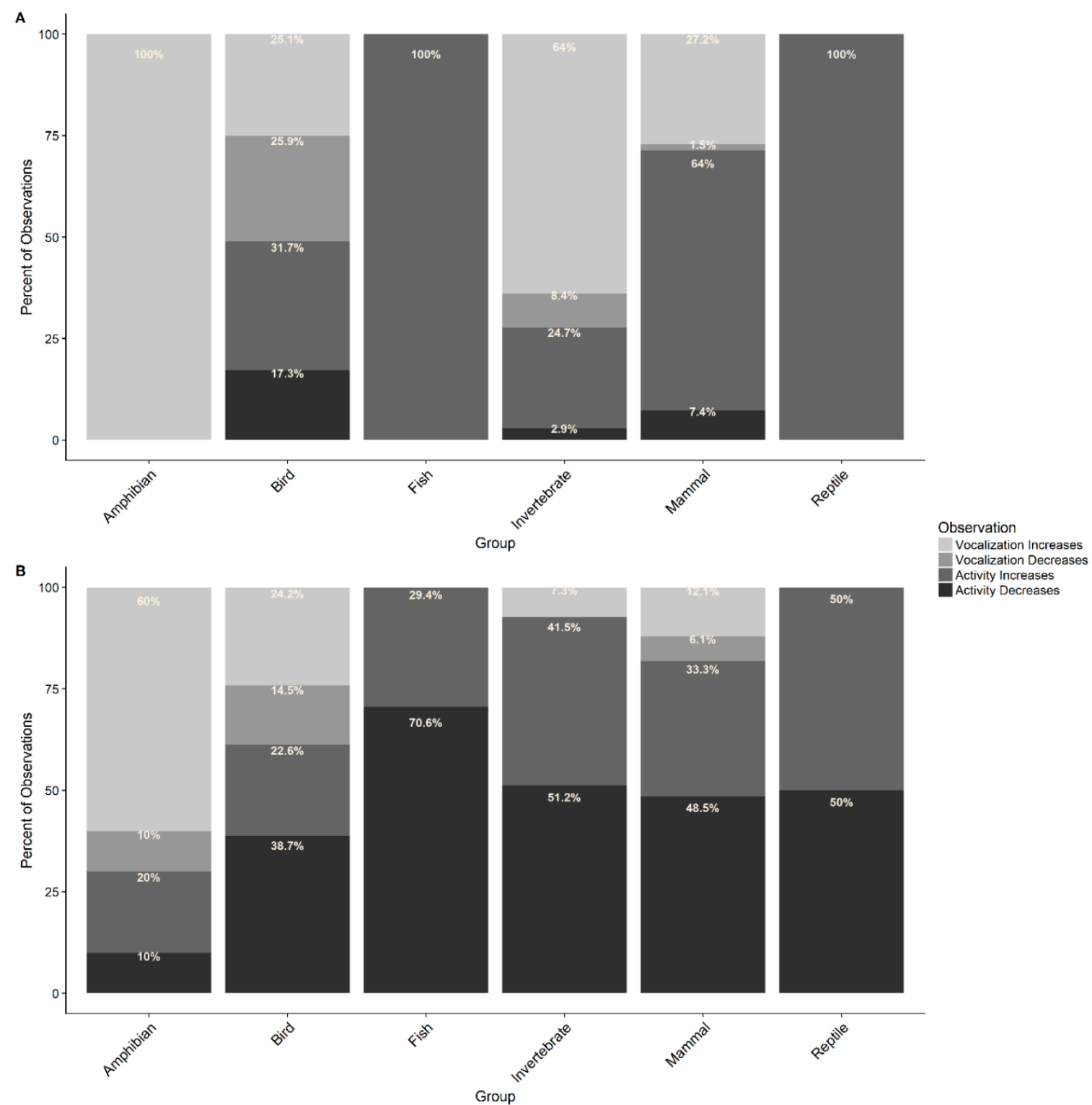

Figure 2. The proportion of behaviors observed for each group of animals recorded by social media (A) and scientific literature $(\mathbf{B})$ is reported as a percent of the total number of observations made for each group of animals by the source (each animal grouping totals $100 \%$ in each source type). All observations were classified into one of four behaviors (vocalization increase, vocalization decrease, activity increase, or activity decrease).

\subsection{Scientific Literature: Published Observations of Behavior from Previous Eclipses}

A total of 169 behavior observations for approximately 131 different animal species were recorded in the published literature (Table 2). The majority of observations came from Wheeler et al. (1935) [7] (54\% of literature observations), Murdin (2001) (10.7\% of literature observations) [38], and Kullenberg (1955) (10.6\% of literature observations) [39], which also contained notes on a wide diversity of taxa, many of which were collected from the general public observations as well [7]. The remaining studies tended to have a narrower taxonomic focus and explicit hypotheses. 
Table 2. Total number of observations reporting changes in animal behavior during eclipses enumerated from published research.

\begin{tabular}{|c|c|c|c|c|c|c|}
\hline Animal & Group & Citation & $\begin{array}{l}\text { Vocalization } \\
\text { Increase }\end{array}$ & $\begin{array}{c}\text { Vocalization } \\
\text { Decrease }\end{array}$ & $\begin{array}{l}\text { Activity } \\
\text { Increase }\end{array}$ & $\begin{array}{l}\text { Activity } \\
\text { Decrease }\end{array}$ \\
\hline American Toad & Amphibian & [7] & 0 & 0 & 1 & 1 \\
\hline Bullfrog & Amphibian & [7] & 0 & 0 & 1 & 0 \\
\hline Frog & Amphibian & {$[7,38]$} & 2 & 1 & 0 & 0 \\
\hline Tree frog & Amphibian & [40] & 1 & 0 & 0 & 0 \\
\hline Tree toad & Amphibian & [7] & 1 & 0 & 0 & 0 \\
\hline Troschel's tree frog & Amphibian & [41] & 1 & 0 & 0 & 0 \\
\hline Barred owl & Bird & [7] & 1 & 0 & 0 & 0 \\
\hline Black-Crowned Night Heron & Bird & [7] & 0 & 0 & 1 & 0 \\
\hline Blue jay & Bird & [7] & 0 & 1 & 0 & 0 \\
\hline Bronzed grackle & Bird & [7] & 0 & 0 & 0 & 1 \\
\hline Brown pelican & Bird & [9] & 0 & 0 & 0 & 1 \\
\hline Bulbuls & Bird & [38] & 0 & 1 & 0 & 0 \\
\hline Cattle Egrets & Bird & [8] & 0 & 0 & 1 & 0 \\
\hline Chicken & Bird & {$[7,40]$} & 2 & 0 & 1 & 1 \\
\hline Common blackbird & Bird & [39] & 1 & 0 & 0 & 0 \\
\hline Common chaffinch & Bird & [39] & 0 & 1 & 0 & 0 \\
\hline Common tern & Bird & [7] & 1 & 0 & 0 & 0 \\
\hline Crow & Bird & {$[7,40]$} & 0 & 0 & 1 & 2 \\
\hline Dowitcher & Bird & [7] & 1 & 1 & 1 & 0 \\
\hline Ducks & Bird & {$[7]$} & 0 & 0 & 1 & 0 \\
\hline Egret & Bird & [38] & 0 & 0 & 0 & 1 \\
\hline Eurasian blackcap & Bird & [39] & 1 & 0 & 0 & 0 \\
\hline European robin & Bird & [39] & 1 & 0 & 1 & 0 \\
\hline Fish hawk & Bird & [7] & 1 & 0 & 1 & 0 \\
\hline Garden warbler & Bird & [39] & 0 & 1 & 0 & 0 \\
\hline Geese & Bird & [38] & 0 & 0 & 0 & 1 \\
\hline Glossy starlings & Bird & [38] & 0 & 1 & 0 & 0 \\
\hline Goldfinch & Bird & {$[7]$} & 0 & 0 & 0 & 1 \\
\hline Great Egrets & Bird & [8] & 0 & 0 & 1 & 0 \\
\hline Herring gull & Bird & {$[7]$} & 0 & 0 & 0 & 1 \\
\hline Ibis & Bird & [38] & 0 & 0 & 0 & 1 \\
\hline Least sandpiper & Bird & {$[7]$} & 0 & 0 & 0 & 0 \\
\hline Little Blue Herons & Bird & [8] & 0 & 0 & 1 & 0 \\
\hline Magnificent frigate-bird & Bird & [9] & 0 & 0 & 0 & 1 \\
\hline Northern flicker & Bird & [7] & 0 & 0 & 0 & 1 \\
\hline Owl & Bird & [38] & 1 & 0 & 0 & 0 \\
\hline Oxpecker & Bird & [38] & 0 & 0 & 0 & 1 \\
\hline Pectoral sandpiper & Bird & [7] & 0 & 0 & 0 & 1 \\
\hline Red-winged blackbird & Bird & [7] & 0 & 0 & 0 & 1 \\
\hline Robin & Bird & [7] & 0 & 0 & 0 & 1 \\
\hline Roseate tern & Bird & [7] & 1 & 0 & 0 & 0 \\
\hline Royal tern & Bird & [9] & 0 & 0 & 0 & 1 \\
\hline Screech owl & Bird & [7] & 1 & 0 & 0 & 0 \\
\hline Semipalmated plover & Bird & [7] & 0 & 0 & 0 & 1 \\
\hline Semipalmated sandpiper & Bird & [7] & 0 & 0 & 0 & 1 \\
\hline Snowy egrets & Bird & [8] & 0 & 0 & 1 & 0 \\
\hline Song thrush & Bird & [39] & 0 & 1 & 0 & 0 \\
\hline Starling & Bird & [7] & 0 & 0 & 1 & 0 \\
\hline Trumpeter hornbill & Bird & [38] & 0 & 0 & 0 & 1 \\
\hline Turtle-dove & Bird & [38] & 0 & 1 & 0 & 0 \\
\hline Water birds & Bird & [38] & 0 & 0 & 0 & 1 \\
\hline Whip-poor-will & Bird & [7] & 1 & 0 & 0 & 0 \\
\hline Willet & Bird & [7] & 1 & 0 & 1 & 0 \\
\hline Willow warbler & Bird & [39] & 0 & 1 & 0 & 0 \\
\hline Wilson's petrel & Bird & [7] & 0 & 0 & 0 & 1 \\
\hline Angelfish & Fish & {$[25]$} & 0 & 0 & 0 & 1 \\
\hline Anthias & Fish & [25] & 0 & 0 & 0 & 1 \\
\hline Banded gourami & Fish & [24] & 0 & 0 & 0 & 1 \\
\hline Brook Trout & Fish & [7] & 0 & 0 & 1 & 1 \\
\hline Butterflyfish & Fish & {$[25]$} & 0 & 0 & 0 & 1 \\
\hline Climbing perch & Fish & [24] & 0 & 0 & 0 & 1 \\
\hline
\end{tabular}


Table 2. Cont.

\begin{tabular}{|c|c|c|c|c|c|c|}
\hline Animal & Group & Citation & $\begin{array}{l}\text { Vocalization } \\
\text { Increase }\end{array}$ & $\begin{array}{l}\text { Vocalization } \\
\text { Decrease }\end{array}$ & $\begin{array}{l}\text { Activity } \\
\text { Increase }\end{array}$ & $\begin{array}{l}\text { Activity } \\
\text { Decrease }\end{array}$ \\
\hline Common Pickerel & Fish & [7] & 0 & 0 & 1 & 0 \\
\hline Damselfish & Fish & [25] & 0 & 0 & 0 & 1 \\
\hline Goldfish & Fish & [7] & 0 & 0 & 1 & 1 \\
\hline Hawkfish & Fish & [25] & 0 & 0 & 0 & 1 \\
\hline Mud eel & Fish & [24] & 0 & 0 & 0 & 1 \\
\hline White perch & Fish & [7] & 0 & 0 & 1 & 0 \\
\hline Wrasse & Fish & [25] & 0 & 0 & 0 & 1 \\
\hline Bees & Invertebrate & [38] & 0 & 0 & 0 & 1 \\
\hline Bumblebees & Invertebrate & [7] & 0 & 0 & 0 & 1 \\
\hline Butterflies & Invertebrate & {$[7,38]$} & 0 & 0 & 0 & 2 \\
\hline Cercariae & Invertebrate & [42] & 0 & 0 & 1 & 0 \\
\hline Cicadas & Invertebrate & [7] & 1 & 0 & 0 & 0 \\
\hline Cockroaches & Invertebrate & {$[7]$} & 0 & 0 & 1 & 0 \\
\hline Crabro vagus & Invertebrate & [39] & 0 & 0 & 0 & 1 \\
\hline Crickets & Invertebrate & [7] & 1 & 0 & 0 & 0 \\
\hline Dinoflagelletes & Invertebrate & [15] & 0 & 0 & 1 & 0 \\
\hline European rose chafer & Invertebrate & [39] & 0 & 0 & 0 & 1 \\
\hline Fucellina fly & Invertebrate & [40] & 0 & 0 & 0 & 1 \\
\hline Glanville fritillary & Invertebrate & [39] & 0 & 0 & 0 & 1 \\
\hline Gnats & Invertebrate & [7] & 0 & 0 & 1 & 0 \\
\hline Gorytes campestris & Invertebrate & [39] & 0 & 0 & 0 & 1 \\
\hline Gorytes mystaceus & Invertebrate & [39] & 0 & 0 & 0 & 1 \\
\hline Grasshoppers & Invertebrate & {$[7,39]$} & 0 & 0 & 0 & 2 \\
\hline Hoplomerus melanocephalus & Invertebrate & [39] & 0 & 0 & 0 & 1 \\
\hline Houseflies & Invertebrate & [7] & 0 & 0 & 1 & 1 \\
\hline Katydids & Invertebrate & [7] & 1 & 0 & 0 & 0 \\
\hline Large-spurred digger wasp & Invertebrate & [39] & 0 & 0 & 0 & 1 \\
\hline Midge & Invertebrate & {$[38,40]$} & 0 & 0 & 2 & 0 \\
\hline Mosquitoes & Invertebrate & {$[7,38]$} & 0 & 0 & 2 & 0 \\
\hline Moths & Invertebrate & [7] & 0 & 0 & 1 & 0 \\
\hline Orb-weaving spider & Invertebrate & [13] & 0 & 0 & 1 & 0 \\
\hline Rock bees & Invertebrate & [10] & 0 & 0 & 1 & 0 \\
\hline Sahara Desert ant & Invertebrate & [11] & 0 & 0 & 0 & 1 \\
\hline Slender bodied digger wasp & Invertebrate & {$[39]$} & 0 & 0 & 0 & 1 \\
\hline Wasps & Invertebrate & [7] & 0 & 0 & 0 & 1 \\
\hline Zooplankton & Invertebrate & [16-19] & 0 & 0 & 4 & 2 \\
\hline Antelope ground squirrel & Mammal & [26] & 0 & 0 & 1 & 0 \\
\hline Baboon & Mammal & [38] & 0 & 0 & 0 & 1 \\
\hline Bat & Mammal & [7] & 0 & 0 & 1 & 0 \\
\hline Beaver & Mammal & {$[7]$} & 0 & 0 & 1 & 1 \\
\hline Blue Bull Antelope & Mammal & [32] & 0 & 0 & 0 & 1 \\
\hline Bush rat & Mammal & {$[27]$} & 0 & 0 & 0 & 1 \\
\hline Chimpanzee & Mammal & [20] & 0 & 0 & 1 & 0 \\
\hline Guinea-pig & Mammal & [7] & 0 & 0 & 0 & 1 \\
\hline Hamadryas baboon & Mammal & [21] & 0 & 0 & 0 & 1 \\
\hline Hippopotamus & Mammal & {$[38]$} & 0 & 0 & 1 & 0 \\
\hline Impala & Mammal & [38] & 0 & 0 & 0 & 1 \\
\hline Proboscis Monkey & Mammal & [23] & 0 & 0 & 0 & 1 \\
\hline Red fox & Mammal & [7] & 1 & 0 & 1 & 0 \\
\hline Rhesus monkey & Mammal & [7] & 0 & 0 & 0 & 1 \\
\hline Skunk & Mammal & [7] & 0 & 0 & 1 & 0 \\
\hline Eastern garter snake & Reptile & [7] & 0 & 0 & 1 & 0 \\
\hline $\begin{array}{c}\text { North American } \\
\text { side-blotched lizard }\end{array}$ & Reptile & [31] & 0 & 0 & 1 & 0 \\
\hline Northern watersnake & Reptile & [7] & 0 & 0 & 0 & 1 \\
\hline Painted turtle & Reptile & [7] & 0 & 0 & 0 & 1 \\
\hline Pythons & Reptile & [7] & 0 & 0 & 1 & 0 \\
\hline Zebra-tailed lizard & Reptile & [30] & 0 & 0 & 0 & 1 \\
\hline
\end{tabular}


The group with the highest number of observations in the literature were birds with 62 records (37\% of literature observations; Figure 1B) of 51 species responding to solar eclipse, the majority of which were chickens (7.8\% of bird observations). Most observations reported decreases in activity (38.7\% of bird observations) followed by increases in vocalization (24.2\% of bird observations; Figure $2 \mathrm{~B}$ ). There were approximately 30 different species of invertebrate observed ( $24 \%$ of literature observations; Figure 1B), most frequently reported of which were zooplankton (14.6\% of invertebrate observations). The most commonly reported behavior was a decrease in activity ( $51.2 \%$ of invertebrate observations) followed by activity increase ( $41.5 \%$ of invertebrate observations; Figure $2 \mathrm{~B}$ ). Interestingly, increases in vocalization were reported in $7.3 \%$ of observations while none mentioned decreases in vocalization (Figure $2 \mathrm{~B}$ ). The literature reported observations for approximately 22 different mammal species ( $20 \%$ of literature observations; Figure $1 \mathrm{~B}$ ) with the most numerous records being of dogs and gray squirrels ( $12.1 \%$ of mammal observations each) followed by cats $(9.1 \%$ of mammal observations). The most commonly reported mammal behavior was a decrease in activity (48.5\% of mammal observations) followed by increase in activity (33.3\% of mammal observations; Figure 2B). There were 14 different species of fish recorded in the literature to respond to a solar eclipse $(10 \%$ of literature observations; Figure 1B). The most common species to respond were the small-mouth black bass, goldfish, and brook trout (11.8\% of fish observations each). The most frequently recorded behavior for fish was a decrease in activity (70.6\% of fish observations; Figure 2B). Observations of amphibian species were least precisely reported but comprised of frogs and toads of various species and totaled ten observations in all ( $6 \%$ of literature observations; Figure 1B). The most frequently reported behavior change was an increase in vocalization (60\% of amphibian observations; Figure 2B). Observations of reptiles comprised two species of lizard, three species of snake, and one species of turtle ( $4 \%$ of literature observations; Figure 1B). Each species had only one observation and reports of activity increase and decrease were recorded with equal frequency (50\% of reptile observations each; Figure $2 \mathrm{~B}$ ).

\section{Discussion}

The scientific literature encompassed multiple eclipse events but contained fewer total observations than social media which only pertained to a single eclipse, however, the overall proportion of observations was similar for each animal group. In general, social media observations focused on increases in vocalization and activity while scientific literature favored activity over vocalization observations. By taxa, observations of birds, invertebrates, and mammals were more common than those of amphibians, fish, and reptiles. However, the literature tended to report a higher diversity of behavioral changes than social media.

There are numerous factors associated with a solar eclipse that may be the root cause of the observed behavioral changes. Not only is there a change in light, but also changes in air temperature and wind speed [4]. It is possible that the brief changes in temperature and wind speed are sensed by animals and, in combination with reduced light, are interpreted as the beginning of nocturnal changes or large storm, potentially enhancing bird and invertebrate vocalizations as instinctive behavior. The specific response by an individual of any species will depend on their specific life history and behavioral patterns associated with nocturnal changes [7] or a large storm, which can also decrease light via cloud cover.

Social media has potential utility to this kind of research because the large numbers observations gathered by this outlet can capture a wider spectrum of species and behaviors, highlighting topics of further exploration by researchers. The high prevalence of records for invertebrates and birds on social media is compelling for future research. Though covered in similar proportions within the literature relative to the other categories, additional scientific studies focusing on these taxa are likely to be fruitful. Considering the documented role celestial cues have on the orientation of birds [43-45] and insects [1,14], there are a number of potential factors to examine why these taxa would respond to such phenomena, which may also include behavioral responses to anomalies such as geomagnetic-electromagnetic changes (i.e., associated to impending earthquakes, i.e., [46]. It is also 
interesting to note that reports of decreases in invertebrate vocalization were found in social media but no such observations were present in the scientific literature. This may suggest an additional area of research requiring attention. Only a single type of behavior was reported for amphibians, fish, and reptiles through social media, which could be factor of people not looking at these species during an eclipse, regardless multiple responses were recorded in the scientific literature. It is worth noting for these taxa that even though the overall proportion of observations from these sources differed, they each had a similar total number of reports for these groups. Interestingly, a higher proportion of fish observations in the scientific literature reported a decrease in activity while only an increase in activity was reported on social media.

The major differences in behavioral observations between these sources may be due to the amateur nature of the social media records. Using social media, we do not know the participants or how reliable the information they provided may or may not be. This is a shortcoming of social media data, but given our goal of identifying gaps in the published research with regards to the taxonomic group or generalized behaviors that are potentially understudied or undervalued with regards to their response to a solar eclipse, we believe that the social media data was suitable. However, for more detailed analyses of specific species or behaviors, a more formalized citizen science approach would be necessary.

Though similar such accounts appear in the literature [7], the observational methodology for this type of research is congruent to how the social media investigations were conducted. The underlying mechanisms responsible for observed differences within and between groups is likely related to their specific life histories and characteristics. For instance, fish and reptiles do not typically produce vocalizations audible to casual observers, which supports why this response was not recorded in the literature (Table 2) or on social media (Table 1). Other influences of behavioral responses are extensively covered in the literature [1]. In order to test these differences and examine their causes, research on this question needs to become more rigorous. This requires a shift from observational accounts, which dominate the literature, to experimental, quantitative investigations of why, how, and when animals respond to solar eclipses or other natural phenomena. It is clear that more research is necessary to disentangle the numerous influences responsible for these observed behaviors. Such investigations can contribute to the advancement of animal behavior science by increasing our understanding of how external factors influence activity.

\section{Recommendations for Future Research}

It is evident from both the literature and anecdotal observations that behavioral responses of many animals to solar eclipses are highly dependent on the specific animal in question. Overall, our findings indicate that activity generally changes more frequently than vocalization, except for amphibians. Organisms which seem to be understudied in relation to this phenomenon are amphibians, fish, and reptiles. Though all taxa in question need to be further explored to elucidate causes of their responses, these particular groups lack the most in behavioral studies during an eclipse. However, birds and invertebrates seem to offer the richest prospects for these investigations due to their prevalence in accounts from both sources. In order to make reasonable conclusions about an animal's behavioral response to a solar eclipse, a detailed understanding of its life history and prevailing environmental conditions during the period are necessary [7]. Whether an animal responds may also be related to the sensitivity of its underlying biological rhythms to environmental factors [1]. Researchers need to compose clear hypotheses concerning expected and observed behavioral responses based on their specific study organism in order to put their responses into context. It is helpful to consider this type of research as special cases of biological rhythms [15], which can serve as basis for designing experiments to test behavioral responses to solar eclipses. These future experiments should seek to implement new methods and technologies for recording animal behavior, such as GPS transmitters, thermal cameras, drones, etc. Our understanding of animal behavior can progress beyond the narrow 
scope of current studies by characterizing the complex variations in behavioral response which result from a solar eclipse.

Author Contributions: Conceptualization, N.B.; Formal Analysis, R.R.; Supervision, D.H.R.

Funding: This research was funded by a NASA Nebraska Space Grant.

Conflicts of Interest: The authors declare no conflict of interest.

\section{References}

1. Aschoff, J. (Ed.) Handbook of Behavioral Neurobiology; Volume 4, Biological Rhythms; Plenum Press: New York, NY, USA, 1981.

2. Rusak, B.; Zucker, I. Biological rhythms and animal behavior. Annu. Rev. Psychol. 1975, 26, $137-171$. [CrossRef] [PubMed]

3. Kalmus, H. Comparative physiology: Navigation by animals. Annu. Rev. Psychol. 1964, 26, 109-130. [CrossRef] [PubMed]

4. Burt, S. Meteorological impacts of the total solar eclipse of 21 August 2017. Weather 2018, 73, 90-95. [CrossRef]

5. Pasachoff, J.M. Scientific observations at total solar eclipses. Res. Astron. Astrophys. 2009, 9, 613-634. [CrossRef]

6. Hughes, S.; Wimmer, J.; Towsey, M.; Fahmi, M.; Winslett, G.; Dubler, G.; Le Prou, A.; Loose, D. The greatest shadow on Earth. Phys. Edu. 2013, 49, 88-94. [CrossRef]

7. Wheeler, W.M.; MacCoy, C.V.; Griscom, L.; Allen, G.M.; Coolidge, H.J., Jr. Observations on the behavior of animals during the total solar eclipse of August 31, 1932. Proc. Am. Acad. Arts Sci. USA 1935, 70, 33-70. [CrossRef]

8. MacCarone, A.D. Directions of foraging flights by wading birds during an annular eclipse. Colonial Waterbirds 1997, 20, 537-539. [CrossRef]

9. Tramar, E.J. Bird behavior during a total solar eclipse. Wilson Bull. 2000, 112, 431-432. [CrossRef]

10. Roonwal, M.L. Behaviour of the rock bees, Apis dorsata Fabr., during a partial solar eclipse in India. Proc. Natl. Acad. Sci. India Sect. B 1957, 22, 281-286.

11. Delye, G. Observations sur le comportement de la fourmi Cataglyphis bicolor (Fabricius) lors d'une eclipse totale de soleil. Insectes Sociaux. 1974, 21, 369-380. [CrossRef]

12. Sanborn, A.F.; Phillips, P.K. Observations of the effect of a partial solar eclipse on calling in some desert cicadas (Homoptera: Cicadidae). Fla. Entomol. 1992, 75, 285-287. [CrossRef]

13. Uetz, G.W.; Hieber, C.S.; Jakob, E.M.; Wilcox, R.S.; Kroeger, D.; McCrate, A.; Mostrom, A.M. Behavior of colonial orb-weaving spiders during a solar eclipse. Ethology 1994, 96, 24-32. [CrossRef]

14. Ugolini, A.; Castellini, C.; Tiribilli, B. The orientation of the sandhopper Talitrus saltator during a partial solar eclipse. J. Comp. Physiol. A 2004, 190, 855-859. [CrossRef] [PubMed]

15. Backus, R.H.; Clark, R.C.; Wing, A.S. Behaviour of certain marine organisms during the solar eclipse of July 20, 1963. Nature 1965, 205, 989-991. [CrossRef]

16. Bright, T.; Ferrari, F.; Martin, D.; Francheschini, G.A. Effects of a total solar eclipse on the vertical distribution of certain oceanic zooplankters. Limnol. Oceanogr. 1972, 17, 296-301. [CrossRef]

17. Cadwallader, P.L.; Eden, A.K. Effect of a total solar eclipse on invertebrate drift in Snobs Creek, Victoria. Aust. J. Mar. Freshw. Res. 1977, 28, 799-805. [CrossRef]

18. Pratiwi, N.T.M.; Zulmi, R.; Mulyawati, D.; Sulaiman, G.S.A. The existence of phytoplankton and zooplankton during solar eclipse in a single spot of Pramuka Island waters, Seribu Islands. IOP Conf. Ser. Earth Environ. Sci. 2017, 54, 1-9. [CrossRef]

19. Adhikari, S.; Goswami, A.R.; Roy, U.S.; Aich, A.; Datta, K. Effect of a total solar eclipse on the surface crowding of zooplankton in a freshwater lake ecosystem. Limnology 2018, 19, 253-270. [CrossRef]

20. Branch, J.E.; Gust, D.A. Effect of solar eclipse on the behavior of a captive group of chimpanzees (Pan troglodytes). Am. J. Primatol. 1986, 11, 367-373. [CrossRef]

21. Gil-Burmann, C.; Beltrami, M. Effect of solar eclipse on the behavior of a captive group of hamadryas baboons (Papio hamadryas). Zoo Biol. 2003, 22, 299-303. [CrossRef]

22. Nakamura, M.; Hitonaru, N. An annular solar eclipse at Mahale: Did chimpanzees exhibit any response? Pan Afr. News. 2016, 23, 9-13. [CrossRef] 
23. Shanida, S.S.; Lestari, T.H.; Partasasmita, R. The effect of total eclipse on the daily activites of Nasalis larvatus (Wurmb.) in Mangrove Center, Kariangau, East Kalimantan. J. Phys. Conf. Ser. 2016, 771, 1-4. [CrossRef]

24. Pandey, K.; Shukla, J.P. Behavioural studies of freshwater fishes during a solar eclipse. Environ. Biol. Fishes. 1982, 7, 63-64. [CrossRef]

25. Jennings, S.; Bustamante, R.H.; Collins, K.; Mallinson, J. Reef fish behavior during a total solar eclipse at Pinta Island, Galapagos. J. Fish Biol. 1998, 53, 683-686.

26. Kavanau, J.L.; Rischer, C.E. Ground squirrel behaviour during a partial solar eclipse. Boll. Zool. 1973, 40, 217-221. [CrossRef]

27. Advani, R. Some observations on behaviour of rodents during solar eclipse. J. Bombay Nat. Hist. Soc. 1981, 78, 590-591.

28. Krzanowski, A. Behaviour of bats during the total solare eclipse in Poland on June 30th, 1954. Acta Theriol. 1959, II, 281-283.

29. Sanchez, O.; Vargas, J.A.; Lopez-Forment, W. Observations of bats during a total solar eclipse in Mexico. Southwest. Nat. 1999, 44, 112-115.

30. Ortega-Rubio, A.; Galina-Tessaro, P.; Alverez-Cardenas, S. Behavior of the zebra-tailed lizard during a total solar eclipse. Tex. J. Sci. 1994, 46, 121-126.

31. Alvarez-Cardenas, S.; Ortega-Rubio, A.; Galina-Tessaro, P.; Vega-Villasante, F. Observations on behavior of the lizard Uta stansburiana during a total solar eclipse. Southwest. Nat. 1997, 42, 108-112.

32. Mahato, A.K.R.; Majumder, S.S.; De, J.K.; Ramakrishna, A. Activities of blue bull, Boselaphus tragocamelus during partial solar eclipse: A case study in captivity. Ethnol. Ecol. Evolut. 2013, 25, 269-274. [CrossRef]

33. Rutter, S.M.; Tainton, V.; Champion, R.A.; Le Grice, P. The effect of a total solar eclipse on the grazing behavior of dairy cattle. Appl. Anim. Behav. Sci. 2002, 79, 273-283. [CrossRef]

34. Nilsson, C.; Horton, K.G.; Kokter, A.M.; Van Doren, B.M.; Famsworth, A. Aeroecology of a solar eclipse. Biol. Lett. 2018, 14, 1-5. [CrossRef] [PubMed]

35. Brinley Buckley, E.M.; Caven, A.J.; Gottesman, B.L.; Harner, M.J.; Pijanowski, B.C.; Forsberg, M.L. Assessing biological and environmental effects of a total solar eclipse with passive multimodal technologies. Ecol. Indic. 2018, 95, 353-369. [CrossRef]

36. Witze, A. Eclipse promises to reveal mysteries of Sun's corona. Nature 2017, 548, 146-147. [CrossRef] [PubMed]

37. March for Science; Facebook; 2017 August 21. Available online: https://www.facebook.com/groups/ marchforscience/ permalink/2020796228204204/ (accessed on 21 December 2017).

38. Murdin, P. Effects of the 2001 total solar eclipse on African wildlife. Astron. Geophys. 2001, 42, 4.

39. Kullenberg, B. Biological observations during the solar eclipse in southern Sweden (Province of Oland) on 30th June 1954. Oikos 1955, 6, 51-60. [CrossRef]

40. Mori, S. Effects of the total solar eclipse on the rhythmic diurnal activities of some animals. Annot. Zool. Jpn. $1939,18,115-132$.

41. Lescure, J. The effect of a total sun eclipse on the vocal behavior of some amphibians. Copeia 1975, 1975, 764-765. [CrossRef]

42. Madhavi, R. Effect of solar eclipse on the emergence of some freshwater cercariae. Proc. Indian Acad. Sci. USA 1983, 92, 65-71. [CrossRef]

43. Emlen, S.T. The stellar-orientation system of a migratory bird. Sci. Am. 1975, 233, 102-111. [CrossRef] [PubMed]

44. Wiltschko, R.; Munro, U.; Ford, H.; Wiltschko, W. Orientation in migratory birds: Time-associated relearning of celestial cues. Anim. Behav. 2001, 62, 245-250. [CrossRef]

45. Diego-Rasilla, E.J.; Luengo, R.M. Celestial orientation in the marbled newt (Triturus marmoratus). J. Ethol. 2002, 20, 137-141. [CrossRef]

46. Fidani, C. Biological Anomalies around the 2009 L'Aquila Earthquake. Animals 2013, 3, 693-721. [CrossRef] [PubMed]

(C) 2019 by the authors. Licensee MDPI, Basel, Switzerland. This article is an open access article distributed under the terms and conditions of the Creative Commons Attribution (CC BY) license (http:/ / creativecommons.org/licenses/by/4.0/). 